\title{
Improvement of Hemifacial Spasm after Stent-assisted Coil Embolization for Ipsilateral Vertebral Artery Dissecting Aneurysm
}

\author{
Yuko MiYaZAKI, ${ }^{1}$ Shunji MATSUBARA, ${ }^{1}$ Manabu ISHIHARA, ${ }^{1}$ \\ Yukari Ogawa MinAmI, ${ }^{1}$ Keita KInOSHITA, ${ }^{1}$ Hiroki TAKAI, ${ }^{1}$ \\ Satoshi HIRAI, ${ }^{1}$ Keijirou HARA, ${ }^{1}$ Kenji YAGI, ${ }^{1}$ and Masaaki UNO ${ }^{1}$ \\ ${ }^{1}$ Department of Neurosurgery, Kawasaki Medical School, Kurashiki, Okayama, Japan
}

\begin{abstract}
Microvascular decompression (MVD) is the gold standard in the treatment of hemifacial spasm (HFS), and endovascular surgery has been described as a treatment only for aneurysm-induced HFS in several previous cases. We describe symptomatic HFS caused by a normal vertebral artery (VA) trunk adjacent to the ipsilateral dissecting VA aneurysm completely cured after stent-assisted coil embolization. A 52-year-old man presented with a 2-month history of gradually worsening left HFS. Magnetic resonance imaging (MRI) and cerebral angiography revealed a dissecting VA aneurysm on the left side. Based on the findings from preoperative MRI, not the aneurysmal dome itself, but the VA trunk just distal to the aneurysmal dome was considered likely to be compressing the root exit zone (REZ) of the facial nerve. Stent-assisted coil embolization was conducted for the VA aneurysm, and the stent was deployed to cover the wide neck of the aneurysm and offending zone of the VA trunk simultaneously. HFS started to show improvement just after the procedure and complete disappearance within 1 year. HFS was completely resolved by stenting of the offending artery. Stents may show efficacy for "intra-arterial decompression" by reducing pulsatility against the REZ of the facial nerve due to the thickness and rigidity of the stent metal and delayed endothelialization.
\end{abstract}

Keywords: hemifacial spasm, intracranial stent, neurovascular compression syndrome, vertebral artery dissecting aneurysm

\section{Introduction}

Hemifacial spasm (HFS) involves distressing tonicclonic contractions of the facial muscles, caused by mechanical compression of the root exit zone (REZ) of the facial nerve. ${ }^{1,2)}$ The most commonly identified etiology is ectatic or tortuous loops of normal vessels. However, tumors, arteriovenous malformations, and aneurysms are also sometimes seen as causes of this disorder. ${ }^{3)}$

Currently, microvascular decompression (MVD) remains the gold standard treatment for HFS, providing macroscopic and spatial distance between the nerve and causative vessel using a prosthesis under craniotomy. ${ }^{1)}$

Received April 16, 2020; Accepted July 6, 2020

Copyright@ 2021 by The Japan Neurosurgical Society This work is licensed under a Creative Commons AttributionNonCommercial-NoDerivatives International License.
We experienced a case in which an intracranial stent was placed to assist coil embolization of an unruptured vertebral artery (VA) dissecting aneurysm. As a result, concomitant HFS unexpectedly improved, since the stent covered not only the aneurysmal neck but also the responsible VA trunk at the same time. To the best of our knowledge, this represents the first report to describe complete cure of HFS by intracranial stenting of the responsible artery.

\section{Case Report}

History and examination

A 52-year-old man presented with a 2-month history of spasm which started from the left orbicularis muscle, spreading to the left orbicularis oris muscle. He visited our hospital for further examination and treatment. Neurological examination revealed intermittent facial spasm on the left side. Preoperative angiography and magnetic resonance imaging (MRI) 

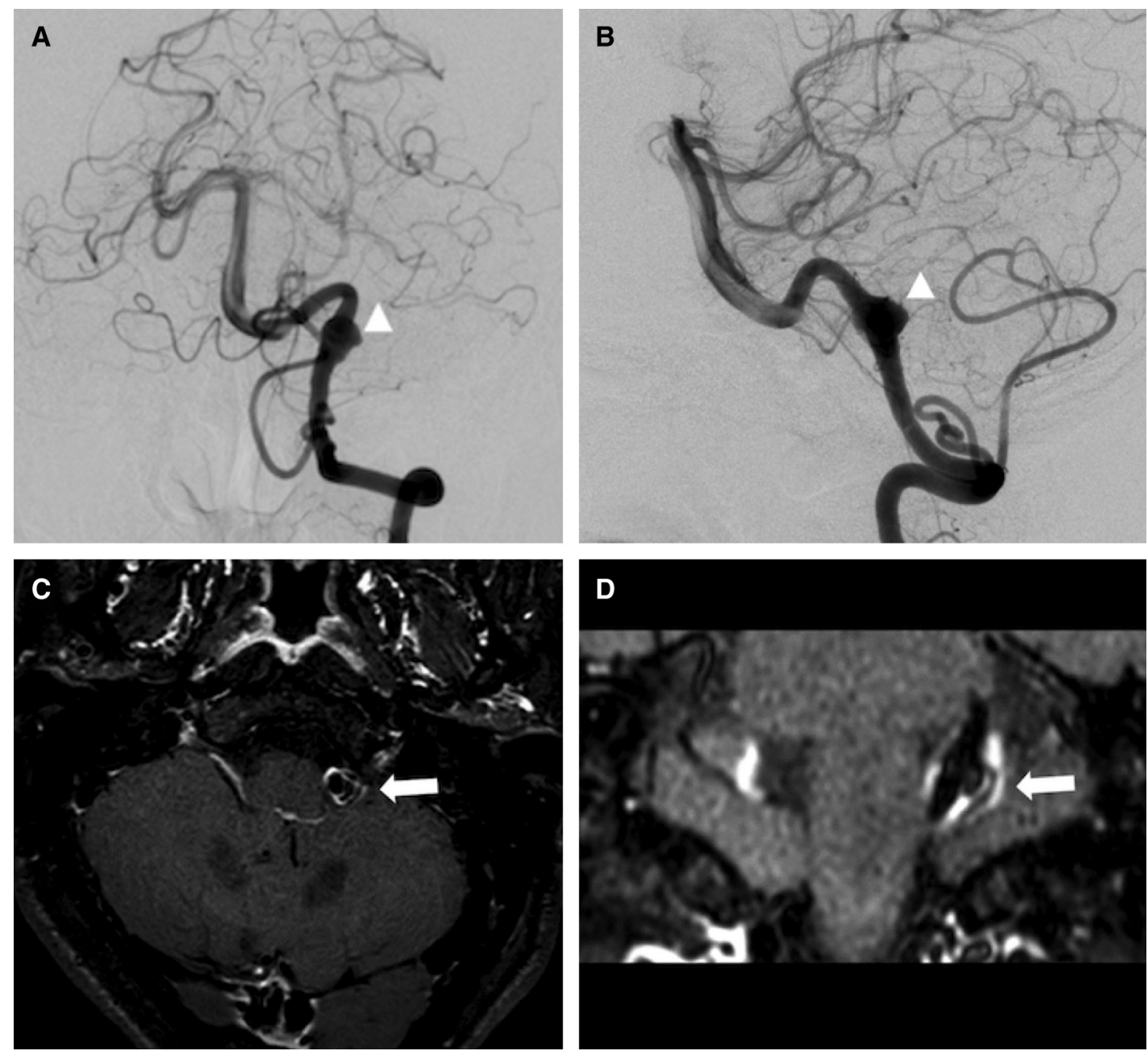

Fig. 1 (A, B) Left vertebral angiogram shows a side wall saccular aneurysm (arrowhead), $8 \times 10 \mathrm{~mm}$ in diameter, arising off the left V4 segment. Left PICA arises from the extracranial portion. No left AICA is apparent (A: frontal view; B: lateral view). (C, D) Contrast enhancement of vessel wall imaging MRI confirms the pseudo-lumen on the dorsolateral aspect of the aneurysm (arrow) (C: axial view; D: coronal view). Note that pathological septation can be detected in this abnormal lumen. AICA: anterior inferior cerebellar artery, MRI: magnetic resonance imaging, PICA: posterior inferior cerebellar artery.

including vessel wall imaging (volume isotropic turbo spin echo acquisition [VISTA]) revealed a dissecting aneurysm $(8 \times 10 \mathrm{~mm})$ arising from the left fourth segment of the VA (Fig. 1). Rather than the aneurysm itself, the normal VA trunk just distal to the aneurysmal dome was considered likely to be compressing the REZ of the facial nerve on source images of magnetic resonance angiography (MRA) (Fig. 2). No other lesions potentially responsible for causing HFS were evident. The patient had neither taken any medication for HFS nor had willing to have MVD done. However, the patient elected to undergo treatment of the aneurysm as a potentially life-threatening pathology. Stent-assisted coil embolization was proposed, to avoid perforator injury or stump thrombosis in the setting of VA sacrifice. This study was approved by the patient consent.

\section{Treatment}

Aspirin at $100 \mathrm{mg} /$ day, clopidogrel at $75 \mathrm{mg} /$ day, and cilostazol at $200 \mathrm{mg} /$ day were administered before the endovascular treatment.

We performed stent-assisted coil embolization using an Enterprise-2 vascular reconstruction device (VRD) $4.0 \times 23 \mathrm{~mm}$ stent (Codman Neurovascular, Miami, FL, USA), one Orbit Galaxy complex coil (Codman \& Shurtleff, Raynham, MA, USA), and nine Target 360 nano coils (Stryker, Fremont, CA, USA) under general anesthesia. The stent was successfully deployed in the parent artery to cover not only the 

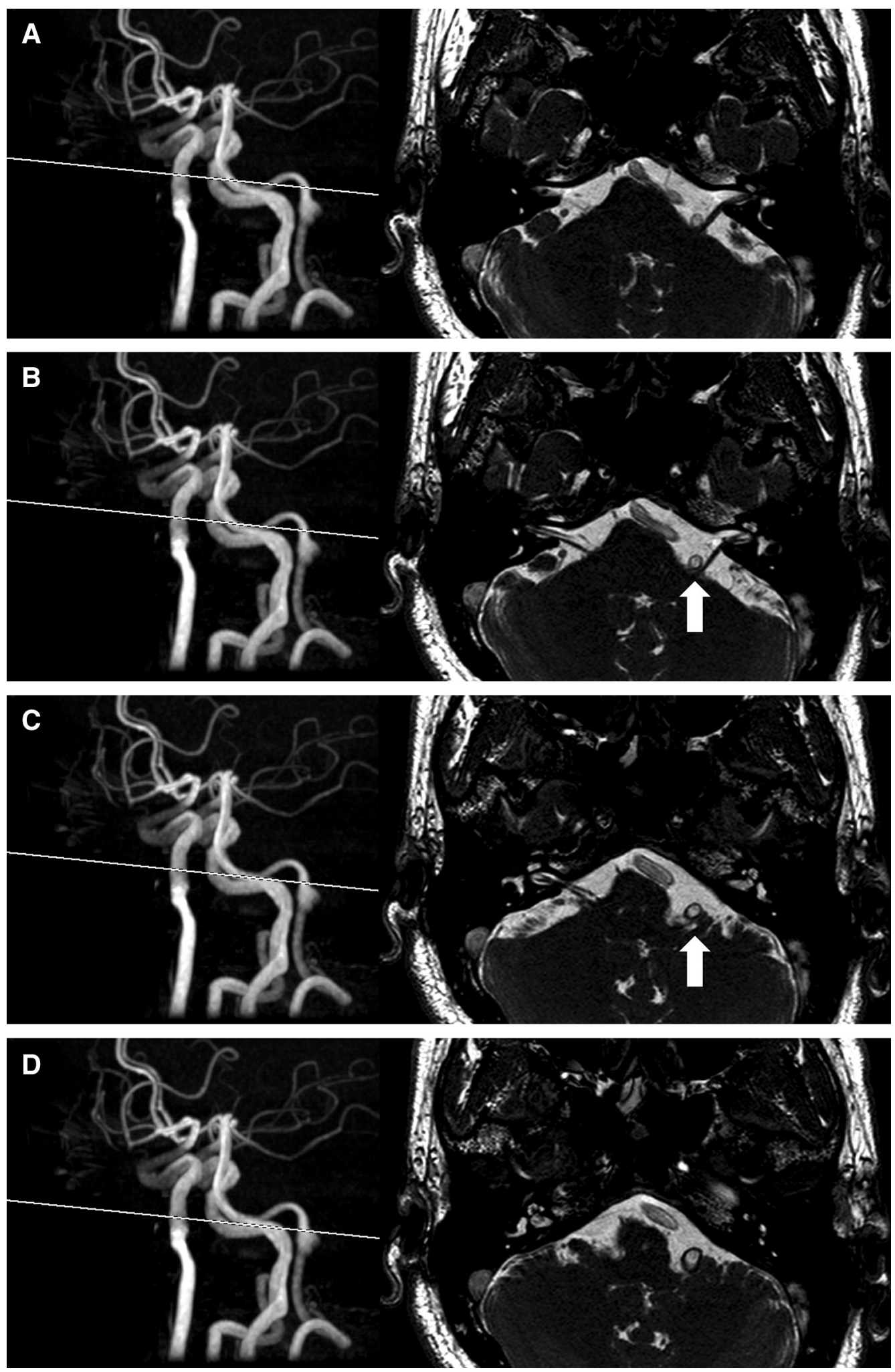

Fig. 2 Consecutive axial images of fast imaging employing steady-state acquisition MRI (3D FIESTA) in accordance with oblique-view of MRA. (A) VA which is distal of aneurysmal dome is unlikely to compress the REZ of cranial nerve VII. (B, C) VA compresses the REZ of the facial nerve at these levels (arrow). (D) Superior aspect of the aneurysmal dome is seen although facial nerve is no more detected at this level. MRA: magnetic resonance angiography, MRI: magnetic resonance imaging, REZ: root exit zone, VA: vertebral artery. 

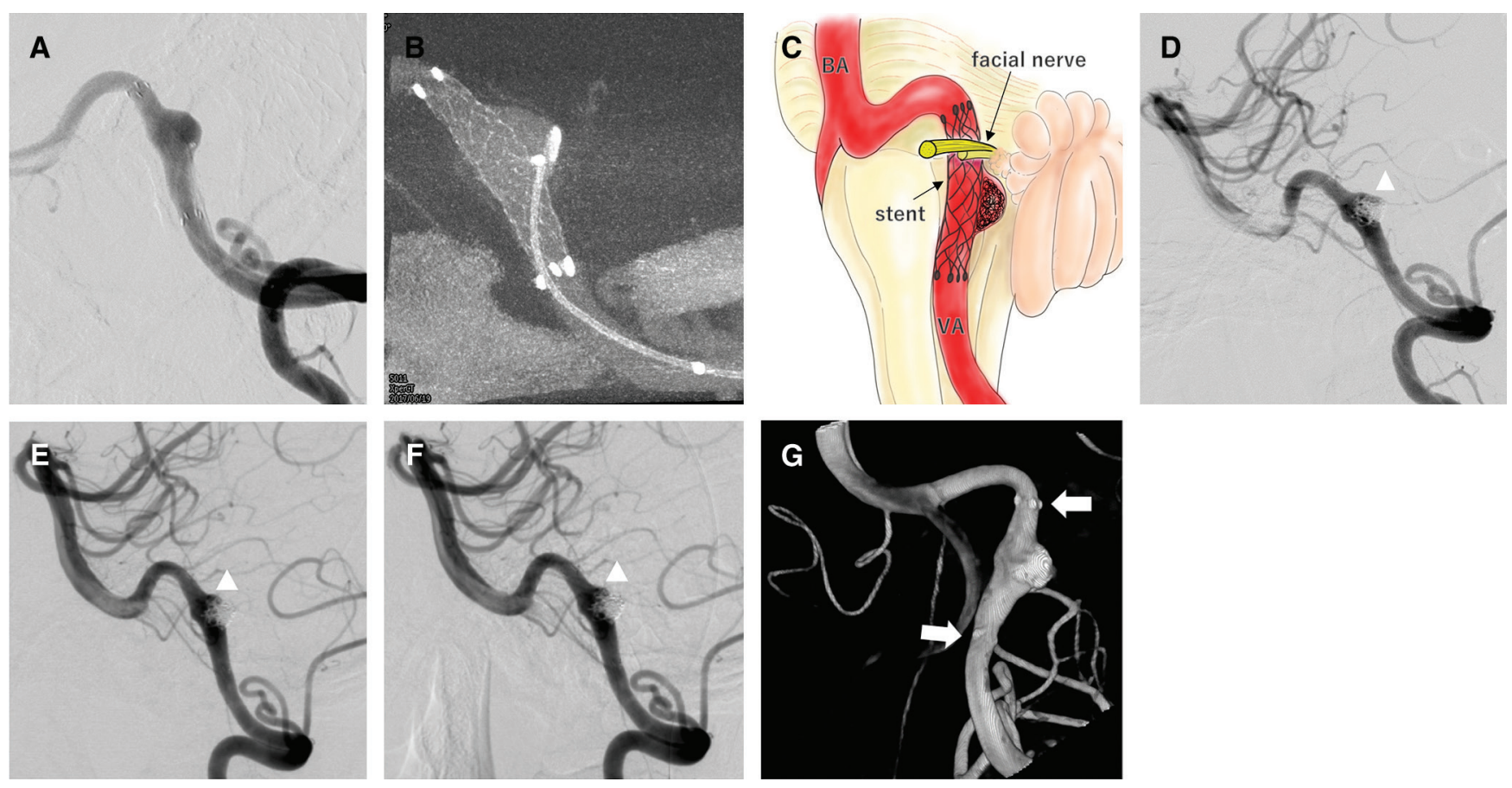

Fig. 3 Left vertebral angiogram (left oblique view (A) and high-resolution cone-beam CT (B)) just after stent deployment. The Enterprise-2 VRD simultaneously covers the aneurysmal neck and VA compressing the REZ. (C) Schema of the postoperative view. The intracranial stent covers not only the wide neck of the aneurysm but also the responsible distal VA. (D) Final lateral image of the procedure. Contrast filling remains slightly evident in rostral aspects of the aneurysmal dome (arrowhead). Fourteen months (E) and 26 months later (F), progression of intra-aneurysmal thrombosis with minimum body filling in the vicinity of the distal neck (arrowhead) is visible on follow-up angiography. At 26 months after coil embolization, 3D rotational angiography (G) reveals the distal and proximal stent markers embedded in the opacified VA, suggesting new endothelialization (arrows). CT: computed tomography, BA: basilar artery, REZ: root exit zone, VA: vertebral artery, 3D: three-dimensional.

aneurysmal neck but also the distal VA trunk as the presumptively offending area (Figs. 3A-3C).

Post-embolization angiography showed sufficient obliteration, but slight contrast flow remained on the rostral side of the dome (Fig. 3D). Postoperative MRI showed asymptomatic cerebral embolism, but no other evidence of complications such as in-stent thrombosis. The patient left our hospital 4 days after embolization and clopidogrel was discontinued at this time.

\section{Postoperative course and follow-up}

Interestingly, HFS started to show improvement just after the procedure and gradually decreased day by day. A reduction of approximately 50\% was obtained within a month and complete resolution was obtained within 1 year. No recurrence of HFS has been noticed during 32 months of follow-up.

Regarding follow-up images, angiography was repeated at 14 and 26 months postoperatively. Lateral views of the left VA injection showed development of intra-aneurysmal thrombosis, but slight body filling in the distal neck remained (Figs. 3E and $3 F)$. Three-dimensional (3D) rotational angiography at 26 months showed stent markers at both ends embedded in the VA opacification, suggesting the formation of new endothelialization on the stent surface (Fig. 3G). MRI at 10 months revealed no significant positional change between offending vessel and the REZ of cranial nerve VII compared with preoperative MRI (Figs. 2 and 4).

\section{Discussion}

MVD is the current gold standard treatment for HFS. However, recent developments in endovascular techniques have contributed to the treatment of aneurysms affecting the REZ in cases where direct surgery is highly difficult. To date, at least six reports have described HFS caused by aneurysm and treated endovascularly, with successful cure achieved in each case (Table 1). ${ }^{4-9)}$

Nagashima et al. ${ }^{4)}$ and Santiago et al. ${ }^{9)}$ reported that there were no changes in the size of aneurysm in contact with the REZ on MRI at the time freedom from symptoms was achieved, despite the disappearance of blood flow in the aneurysm due to 

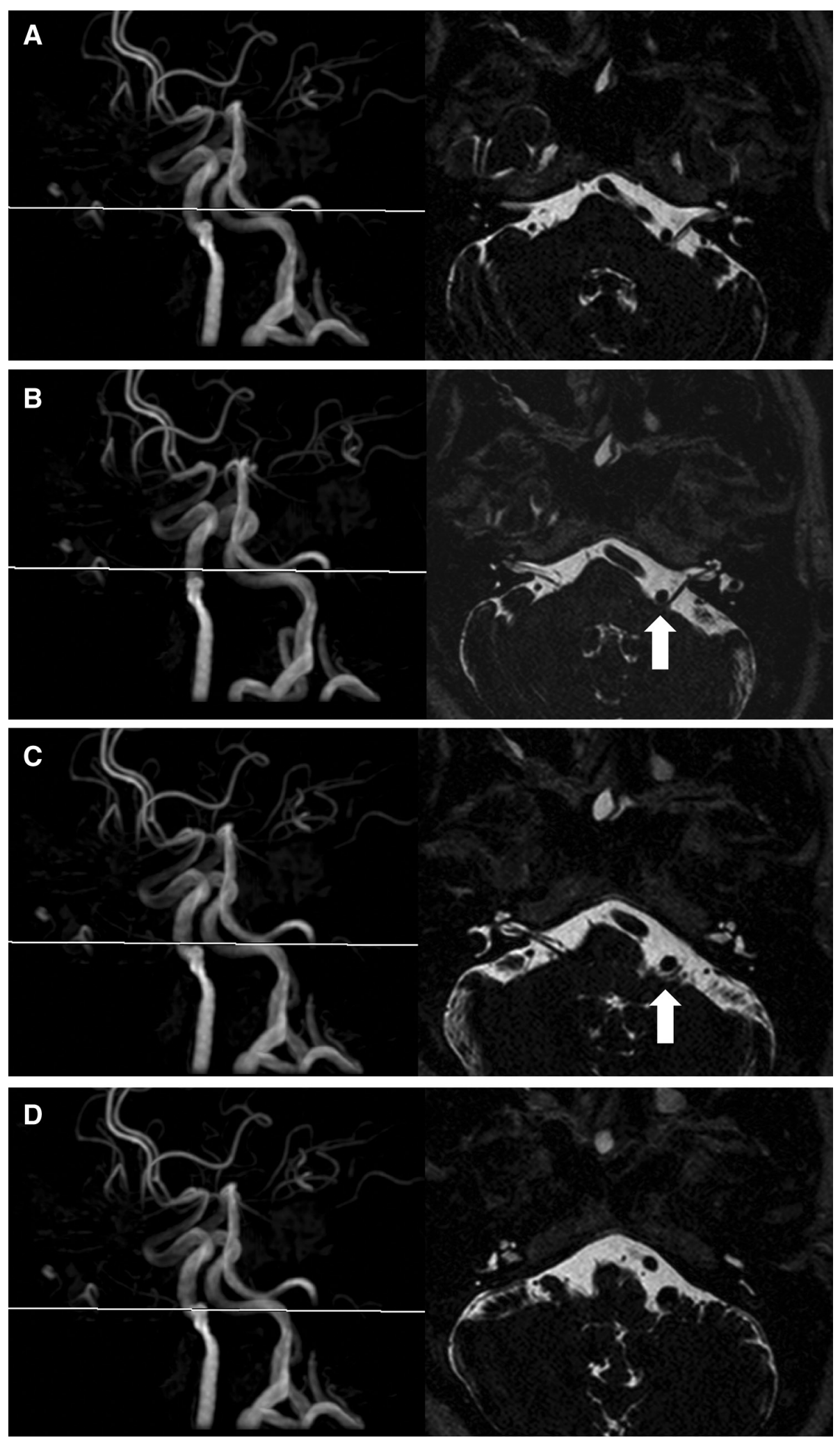

Fig. 4 Postoperative axial images of fast spin echo MRI (3D FASE) at 10 months after the endovascular treatment. There seems to be no significant positional change associated with the facial nerve and the VA. (A, D) The signal of distal VA adjacent to the aneurysm on MRA is invisible because of stent metal artifact. (B, C) VA still compresses the REZ of the facial nerve at these levels as same as Fig. 2 (arrow). MRA: magnetic resonance angiography, MRI: magnetic resonance imaging, REZ: root exit zone, VA: vertebral artery. 
Table 1 Summary of the literatures regarding endovascular treatments for hemifacial spasm caused by vertebrobasilar aneurysm

\begin{tabular}{|c|c|c|c|c|c|c|c|c|c|c|}
\hline Author & Year & Age & $\begin{array}{c}\text { Offending } \\
\text { vasculature }\end{array}$ & Sex & Type & Location & Size & Treatment & $\begin{array}{c}\text { Periods } \\
\text { from onset } \\
\text { to treatment }\end{array}$ & Outcome \\
\hline $\begin{array}{l}\text { Nagashima } \\
\text { et al. }{ }^{4)}\end{array}$ & 2001 & 69 & $\mathrm{AN}$ & $\mathrm{M}$ & $\begin{array}{l}\text { Dissection } \\
\text { fusiform }\end{array}$ & $\begin{array}{l}\text { VA-BA } \\
\text { junction }\end{array}$ & N.A & $\begin{array}{l}\text { Proximal } \\
\text { occlusion }\end{array}$ & 20 months & $\begin{array}{l}\text { CC after } 6 \\
\text { months }\end{array}$ \\
\hline Sato et al. ${ }^{5)}$ & 2001 & 53 & $\mathrm{AN}$ & M & $\begin{array}{l}\text { Dissection } \\
\text { fusiform }\end{array}$ & VA (V4) & $8 \mathrm{~mm}$ & Coil trapping & $\begin{array}{l}\text { More than } \\
51 \text { months }\end{array}$ & $\begin{array}{l}\text { CC after } 6 \\
\text { months }\end{array}$ \\
\hline $\begin{array}{l}\text { Murakami } \\
\text { et al. }{ }^{6)}\end{array}$ & 2004 & 49 & $\mathrm{AN}$ & $\mathrm{F}$ & Saccular & VA (V4) & N.A & Coil trapping & $\begin{array}{l}\text { More than } \\
9 \text { months }\end{array}$ & $\begin{array}{l}\text { CC after } 6 \\
\text { months }\end{array}$ \\
\hline $\begin{array}{l}\text { Matsumoto } \\
\text { et al. }{ }^{7)}\end{array}$ & 2005 & 62 & $\mathrm{AN}$ & $\mathrm{F}$ & Saccular & VA (V4) & N.A & Coil trapping & $\begin{array}{l}\text { More than } \\
6 \text { months }\end{array}$ & $\begin{array}{l}\text { CC after } 3 \\
\text { months }\end{array}$ \\
\hline $\begin{array}{l}\text { Nakagawa } \\
\text { et al. }{ }^{8)}\end{array}$ & 2011 & 55 & $\mathrm{AN}$ & $\mathrm{F}$ & Fusiform & $\begin{array}{l}\text { Near } \\
\text { the VA } \\
\text { union }\end{array}$ & $13 \mathrm{~mm}$ & Coil trapping & 50 months & $\begin{array}{l}\text { CC after } 3 \\
\text { months }\end{array}$ \\
\hline $\begin{array}{l}\text { Santiago } \\
\text { et al. }{ }^{9)}\end{array}$ & 2019 & 60 & $\mathrm{AN}$ & $\mathrm{F}$ & Saccular & VA (V4) & $11 \mathrm{~mm}$ & Flow-diverter & 12 months & $\begin{array}{l}\text { CC after } 6 \\
\text { months }\end{array}$ \\
\hline Ours & 2020 & 52 & $\begin{array}{l}\text { Distal VA } \\
\text { trunk }\end{array}$ & M & $\begin{array}{l}\text { Dissection } \\
\text { fusiform }\end{array}$ & VA (V4) & $10 \mathrm{~mm}$ & $\begin{array}{l}\text { Stent- } \\
\text { assisted coil } \\
\text { embolization }\end{array}$ & 2 months & $\begin{array}{l}\text { CC } \\
\text { after } 12 \\
\text { months }\end{array}$ \\
\hline
\end{tabular}

AN: aneurysm, BA: basilar artery, CC: complete cure, N.A: not applicable, PICA: posterior inferior cerebellar artery, VA: vertebral artery.

thrombosis after endovascular surgery. In addition, endovascular devices such as stents and flow diverters reportedly reduce flow velocity in the aneurysm without changing the pressure inside the aneurysm. ${ }^{10)}$ However, HFS has been improved by flow diverter placement. ${ }^{9)}$ This implies that reducing pulsatility is more important for symptom improvement than decreasing compression on the REZ.

Furthermore, HFS can apparently be improved even with minute positional and hemodynamic changes in the offending vessel, according to a report regarding improvements in HFS after spinal drainage. ${ }^{11)}$ Another report described selective catheterization into the causative vessel as resulting in transient improvement of HFS. ${ }^{12)}$ Moreover, the arterial straightening phenomenon is known to occur frequently after intracranial stenting, and the angle of the stented artery is reported to continue to change between 6 and 34 months after stent deployment. ${ }^{13)}$ In addition, the Enterprise-2 VRD, a closedcell stent, is known to result in more prominent vessel straightening. ${ }^{14,15)}$ The distal VA might move minimally after stent placement, although gross positional changes in the responsible VA area were not apparent on follow-up angiograms (Fig. 3) and MRI (Fig. 4).

In our case, it is difficult to prove pathological endothelialization inside of the stent, but important evidence suggesting new endothelial formation was the fact that markers at both ends of the stent appeared embedded in the VA opacification on 3D rotational angiography at 26 months postoperatively $^{16,17)}$ (Fig. 3G).

Similarly, in-stent restenosis is a well-known complication encountered 3-6 months after coronary stenting. Pathologically, this process has been attributed primarily to neointimal hyperplasia following endothelial injury due to radial force of the stent. ${ }^{18,19)}$ Cerebrovascular stents not used for arteriosclerotic stenosis lesions have been suggested to cause similar changes to a relatively mild degree. ${ }^{20)}$ Actually, in a recent animal experiment, Chun et al. created a nitinol-based intra-arterial neurovascular decompressor mimicking the Enterprise VRD stent in terms of stiffness and deployed it in the femoral artery of a mini-pig. ${ }^{21)}$ Formation of neointima bridging over the device was observed without interrupting the patency of the arterial lumen on histopathological examination using hematoxylin and eosin staining.

Factors associated with improvement of HFS immediately after stent placement are speculated to include the stent mediating decreases in normal arterial pulsation in the causative vessel wall due to the rigidity and additional thickness of the stent metal, and possibly subtle positional changes in the causative vessel through stent-straightening effects. Endothelialization of the inner surface of the stent in response to stent implantation might then develop gradually in the chronic stage, thereby 
further reducing pulsatile force against the REZ day by day. This hypothetical process would seem to explain the gradual improvements in facial spasms.

Lee et al. documented that $41 \%$ of untreated HFS cured spontaneously from 2 months to 23 years in their clinical study. ${ }^{22)}$ However, in our case, the patient realized significant improvement of his unpleasant symptom from just after the endovascular treatment. This fact also suggested an efficacy of our procedure rather than a natural course.

As described above, we experienced the patient with VA aneurysm treated with stent-assisted coil embolization resulting in complete cure of HFS. This unexpected result may imply an alternative treatment for HFS in case of surgical difficulty or elderly people.

\section{Conclusion}

HFS associated with intracranial distal VA started to improve just after the stenting of the offending artery and completely resolved within 1 year. Stents may show efficacy for "intra-arterial decompression" by reducing pulsatility against the REZ of the facial nerve due to the thickness and rigidity of the stent metal and delayed endothelialization.

\section{Acknowledgment}

We thank Ms. Naomi Tamura for her editing efforts of this manuscript.

\section{Conflicts of Interest Disclosure}

None.

\section{References}

1) Lu AY, Yeung JT, Gerrard JL, Michaelides EM, Sekula RFJr, Bulsara KR: Hemifacial spasm and neurovascular compression. Sci World J doi: 10.1155/ 2014/349319.Epub 2014 Oct 28

2) Maroon JC, spasm Hemifacial: A vascular cause. Arch Neurol 35: 481-483, 1978

3) Maroon JC, Lunsford LD, Deeb ZL: Hemifacial spasm due to aneurysmal compression of the facial nerve. Arch Neurol 35: 545-546, 1978

4) Nagashima H, Orz Y, Okudera H, Kobayashi S, Ichinose Y: Remission of hemifacial spasm after proximal occlusion of vertebrobasilar dissecting aneurysm with coils: case report. J Clin Neurosci 8: 43-45, 2001

5) Sato K, Ezura M, Takahashi A, Yoshimoto T: Fusiform aneurysm of the vertebral artery presenting hemifacial spasm treated by intravascular embolization: case report. Surg Neurol 56: 52-55, 2001
6) Murakami H, Kawaguchi T, Fukuda M, Ito Y, Hasegawa H, Tanaka R: Monitoring of the lateral spread response in the endovascular treatment of a hemifacial spasm caused by an unruptured vertebral artery aneurysm. Case report. J Neurosurg 101: 861-863, 2004

7) Matsumoto K, Kimura S, Kakita K: Endovascular treatment of vertebral artery aneurysm manifesting as progressive hemifacial spasm. Neurol Med Chir (Tokyo) 45: 360-362, 2005

8) Nakagawa I, Takayama K, Kurokawa S, et al.: Hemifacial spasm due to contralateral aneurysmal compression of the facial nerve successfully treated with endovascular coil embolization: case report. Neurosurgery 69: E768-E771; discussion E771-762, 2011

9) Santiago-Dieppa DR, McDonald MA, Brandel MG, Rennert RC, Khalessi AA, Olson SE: Endovascular flow diversion for hemifacial spasm induced by a vertebral artery aneurysm: first experience. Oper Neurosurg (Hagerstown) 17: E115-E118, 2019

10) Shobayashi Y, Tateshima S, Kakizaki R, Sudo R, Tanishita K, Viñuela F: Intra-aneurysmal hemodynamic alterations by a self-expandable intracranial stent and flow diversion stent: high intra-aneurysmal pressure remains regardless of flow velocity reduction. $J \mathrm{Neu}$ rointerv Surg 5: iii38-42, 2013

11) Niijima K, Yonekawa Y, Kaku Y: Disappearance of hemifacial spasm following spinal drainage: a case report. Neurol Surg 18: 577-580, 1990

12) Yamashita K, Hojo M, Okamoto S, Kim C, Nakatsu S, Mishima H: Possible role of neurointerventional techniques in the diagnosis of hemifacial spasm. AJNR Am J Neuroradiol 18: 287-290, 1997

13) Cho WS, Kang HS, Kim JE, et al.: Angle change of the parent arteries after stent-assisted coil embolization of wide-necked intracranial bifurcation aneurysms. Clin Radiol 69: e63-70, 2014

14) Chung J, Suh SH, Hong CK, et al.: Preliminary experience with self-expanding closed-cell stent placement in small arteries less than $2 \mathrm{~mm}$ in diameter for the treatment of intracranial aneurysms. J Neurosurg 122: 1503-1510, 2015

15) Gao B, Baharoglu MI, Cohen AD, Malek AM: Stentassisted coiling of intracranial bifurcation aneurysms leads to immediate and delayed intracranial vascular angle remodeling. AJNR Am J Neuroradiol 33: 649654, 2012

16) Ueda Y, Nanto S, Komamura K, Kodama K: Neointimal coverage of stents in human coronary arteries observed by angioscopy. J Am Coll Cardiol 23: 341-346, 1994

17) Wada $T$, Takayama $K$, Myoushin $K$, et al.: Investigation of safe termination of antiplatelet therapy after LVIS stent-assisted cerebral aneurysm coiling. J Neuroendovasc Ther 13: 199-205, 2019

18) Komatsu R, Ueda M, Naruko T, Kojima A, Becker AE: Neointimal tissue response at sites of coronary stenting in humans: macroscopic, histological, and immunohistochemical analyses. Circulation 98: 224-233, 1998 
19) Kipshidze N, Dangas G, Tsapenko M, et al.: Role of the endothelium in modulating neointimal formation: vasculoprotective approaches to attenuate restenosis after percutaneous coronary interventions. $J$ Am Coll Cardiol 44: 733-739, 2004

20) Takemoto K, Tateshima S, Rastogi S, et al.: Disappearance of a small intracranial aneurysm as a result of vessel straightening and in-stent stenosis following use of an Enterprise vascular reconstruction device. BMJ Case Rep 2013: bcr2012010583, 2013

21) Chun Y, Chen Y, Elsisy M, et al.: In vitro and in vivo experiments of a novel intra-arterial neurovascular decompressor for treating neurovascular compression syndromes: a brief report. Neurol Res 41: 665-670, 2019

22) Lee JA, Kim KH, Park K: Natural history of untreated hemifacial spasm: a study of 104 consecutive patients over 5 years. Stereotact Funct Neurosurg 95: 21-25, 2017

Corresponding author: Yuko Miyazaki, MD

Department of Neurosurgery, Kawasaki Medical School, 577 Matsushima, Kurashiki, Okayama 7010192, Japan.

e-mail: yuko.miyayu@gmail.com 